TEXTOS QUE FAZEM HISTÓRIA 


\title{
Urdimento
}

\section{LAUDATIO DE DOUTORADO HONORIS CAUSA A PINA BAUSCH ${ }^{1}$}

\author{
Eugenia Casini Ropa ${ }^{2}$ \\ Tradução de Milton de Andrade
}

Magnífico Reitor e caríssimos colegas, senhor Prefeito e autoridades, senhoras e senhores, a láurea ad honorem que o nosso Ateneu enseja conferir tem características mais do que insólitas. Em primeiro lugar, porque a laureanda é uma mulher, evento raríssimo nestas cerimônias; depois, porque esta mulher é uma artista e não uma estudiosa no sentido próprio do termo, não escreveu livros e nem elaborou teorias ou sistemas complexos. E, por último, porque esta mulher artista provém de um território quase que ignorado pela cultura oficial e pouco considerado também no âmbito das outras artes: a dança.

Quantas desvantagens para uma só pessoa!

E, no entanto, Pina Bausch está hoje conosco, na mais antiga das universidades da Europa, para receber o mais alto dos honores acadêmicos.

Porque Pina Bausch, mulher e artista da dança, contribuiu para mudar a face do teatro da segunda metade deste século que termina, recolhendo a hereditariedade e reelaborando-a criativamente e de modo genialmente peculiar. Compôs obras que nos sondam e nos refletem, nós homens e mulheres deste tempo, tão cândida como impetuosamente, e as elaborou numa forma tão notadamente audaz, porém necessária e orgânica em seu conteúdo, que nos toca a fundo, com aquele provocante e talvez catártico desconforto interior que somente os grandes ritos teatrais sabem induzir.

O Tanztheater, ou seja, teatro de dança, foi desde o início a denominação, simplesmente descritiva, da companhia da Bausch em Wuppertal. Somente mais tarde este termo teria assumido, no país e no exterior, o caráter de uma verdadeira e própria definição de estilo, de um gênero em si mesmo, de enorme influência sobre artistas de todas as partes. Tornou-se somente teatro-dança, forma mista mas coesa, em que dois componentes se fazem gradualmente menos distinguíveis até dar vida a um vínculo totalmente novo e incindível.

${ }^{1}$ Conferência proferida em ocasião do Doutorado honoris causa concedido

a Pina Bausch pela Universidade de Bolonha (Itália) em 25 de Novembro de 1999. [Nota do Editor]. ${ }^{2}$ Eugenia Casini Ropa é professora de História da Dança na Universidade de Bolonha, Itália, diretora do curso de graduação em Disciplinas do Espetáculo e da Associazione Nazionale Danza Educazione Scuola (DES), que promove a dança em âmbito educativo. Estudiosa de teatro e dança do século XX entre suas publicações lembramos especialmente os volumes: La danza e l'agitprop (1988) e Alle origini della danza moderna (1990).

${ }^{3}$ Milton de Andrade é docente do Programa de Pós-Graduação em

Teatro da Universidade do Estado de Santa Catarina (UDESC), com Doutorado em Artes Cênicas pela Universidade de Bolonha (Itália). 


\section{Urdimento}

Na reunificação dos dois termos e dos seus modos expressivos e comunicativos parecia realizar-se um sonho antigo, talvez aquela mítica euritmia constantemente revisitada na história da cultura ocidental moderna, na qual a divisão dos gêneros criou secularmente barreiras quase que insuperáveis. Mas o Tanztheater de Pina Bausch, como se destina ao tempo que o gerou, responde a uma visão de globalidade muito diferente do harmônico sonho totalizante de Wagner e de Appia.

Na tentativa de definir o Tanztheater, muito se fala de um "método" criativo Bausch, mas talvez a única verdadeira metodologia, que Pina Bausch descobriu e seguiu nos anos, seja aquela de eliminar métodos pré-constituídos, aquela da processualidade, da exploração contínua, da necessidade de recolocar cada vez em discussão si mesmo e o próprio trabalho, explorando novos percursos.

Os seus primeiros trabalhos, até a metade dos anos 1970, seguiam ainda substancialmente caminhos coreográficos usuais e elaboravam a partitura dançada a partir de escolhas musicais miradas e específicas. Isto vale tanto para os mais ou menos breves e incisivos rudimentos quase abstratos, que suscitavam o primeiro interesse dos críticos, como para as mais extensas e corais obras dançadas com a música de Gluck. A sua dança é ainda fundamentalmente aquela de estilo moderno e a composição, de cunho intenso e original, visualiza plasticamente a música, desenhando e enfatizando cada íntima razão de ser da partitura, estendendo-se com amplo respiro e sabedoria espacial num todo de compacidade harmônica.

A inquietude e a ânsia de pesquisa começam a infiltrar-se no trabalho de Pina Bausch nos anos imediatamente sucessivos. A música da ópera de Béla Bartok, Barba Azul, é radicalmente fragmentada, balbuciada, assim como a narrativa, que se volta continuamente, atormentada, sobre si mesma. Logo entre as árias clássicas começam a insinuar velhas canções populares, músicas de filmes, jazz e cantos populares; entre os gestos amplos e fluentes da dança moderna se introduzem movimentos rígidos e quebrados ou caricaturais e grotescos, gestos cotidianos repetidos e compostos em cantilenas gestuais; o tecido quase que compacto da composição dramatúrgica se quebra, se divide em quadros, cenas e momentos aproximados e sobrepostos por analogia, por contraste ou por simples casualidade.

No fim dos anos 1970, dá-se início àquele tipo de processo criativo por perguntas, respostas e montagem que se tornará caracterizante, fonte inesgotável de material dramatúrgico e dinâmico. No trabalho em cada nova Stück (peça), como se denominarão ora adiante os espetáculos não mais definíveis com as velhas terminologias, Pina Bausch coloca a seus dançarinos longas séries de perguntas para explorar com eles os temas e os problemas que a assolam naquele momento. 
Com um paciente trabalho maiêutico, às vezes quase que psicanalítico, obtém as suas respostas em palavras, em movimentos, em ações, em música: fragmentos de vivência, recordações, emoções, observações, nas quais as pessoas se revelam, e que se acumulam como preciosa matéria prima teatral. Os dançarinos, até então somente executores, se transformam gradualmente em atores, criadores, produtores de material cênico original, enquanto que Bausch, de coreógrafa, se faz cada vez mais diretora. A dança propriamente dita tende passo a passo a desaparecer, para ressurgir às vezes de improviso em breves sequências de efeito de estranhamento, em caminhadas rítmicas, em inesperadas acrobacias. Muito mais frequentemente é conservada latente sob a superfície, como instrumento de revelação orgânica, de dilatação e de evidência do corpo; corpo que permanece no centro da cena e que é exposto na sua crua fisicalidade e na sua contingente historicidade. Ao movimento corporal se agrega uma outra manifestação, a voz: gritos, risadas, choros, partes de frases, pequenos contos ou poesias, ecos dos muitos sons e palavras que pronunciamos ou que nos atingem a cada dia da vida.

Logo se definem, e incidem com as perguntas nos materiais, as temáticas dominantes: derivam das necessidades, dos medos, das esperanças, das angústias do artista, da sua capacidade de compreender e de compartilhar, do seu olhar penetrante sobre o mundo e seus problemas, numa busca de identidade que é ao mesmo tempo pessoal e histórica. O amor, acima de tudo, em todas as nuances, da ternura ao erotismo, a urgência em dar e receber, e os temores, as dificuldades, as distorções da relação interpessoal, sobretudo de casal. A condição desesperada e ridícula dos universos feminino e masculino, ávidos, mas incapazes de uma real comunicação. E a pesada frustração da mulher destinada a sucumbir ao tosco e violento predomínio masculino. Um jogo de papéis que é jogo de massacre recíproco cruelmente desmascarado, e atenuado por lampejos desencantados, quase afetuosos, de ironia.

Depois as manias, as neuroses, os hábitos deformantes e grotescos da vida cotidiana, suas vazias aparências, clichês que se impõem às pessoas. Mas também, ternamente, as indeléveis recordações da infância e os padecimentos nostálgicos da memória, a leveza dos jogos de crianças e a alegria das pequenas coisas e dos pequenos gestos reconfortantes.

Em sintonia com outros criadores do teatro contemporâneo, a montagem das improvisações temáticas se torna então, para Pina Bausch, a técnica compositiva prevalente, mas nela a construção total do sentido ocorre em termos completamente peculiares, próximos de uma sensibilidade cinematográfica. Mais que sintática ou estratificada, a estrutura de suas peças se apresenta como paratática ou simultânea, os elementos se aproximam frequentemente sem qualquer evidente relação temporal ou de causa e efeito, como numa colagem multicor de materiais diversos. As músicas, presentes 


\section{Urdimento}

somente de tanto em tanto, diversas e contrastantes, antigas e modernas, de arte e de consumo, sempre emocionais, às vezes instrumentais e rétro até próximas do kitsch, envolvem ações e pensamentos, e acrescentam a sensação de acúmulo sensorial e emotivo. Fragmentos dos mundos interior e exterior, imagens brevemente colhidas ou recuperadas do armazém da memória, sonhos, tormentos, visões, lutas e jogos, carícias e feridas, produtos da alma e da vida real, ações, movimentos, palavras, músicas, sons, cores, odores, objetos, materiais, se compõem assim num arranjo inquietante, despedaçado e repetitivo, ao qual serve sempre de agregador algum elemento unificador que recobre a cena, no mais nua. Terra, água, folhas, flores, cactos, caixas ou tijolos fornecem de fato o leitmotiv material e uma moldura simbólica aos disparatados acontecimentos que se desenvolvem.

E no mais, por último, pela extraordinária sensibilidade rítmica de Pina Bausch, pela sua insuperável medida na desmedida, esta desconcertante e babélica colagem milagrosamente acaba por concluir-se num único e envolvente desenho, que parece conservar na alcançada compacidade a provisoriedade de um mundo à beira da crise.

Espelho deformante, mas fiel da desarticulação e multiplicidade do sistema de relações e de vida no qual estamos imersos, o Tanztheater de Pina Bausch é, então, uma dança do teatro ao mesmo tempo macabra e apotropaica: um feliz ritual artístico de fim de século. Herdeiro da ironia e do grotesco da dança expressionista e do Kabarett alemão - pós-brechtiano pela relação com o cotidiano, o estranhamento constante e a direção de montagem de direção; pós-artaudiano pela centralidade que assume a linguagem corporal - o Tanztheater de Pina Bausch ativa essas ascendências no interior de modalidades de pensamento e de criação artística estreitamente contemporâneas. Desintegração e perda de significação das linguagens, contaminações e passagens entre arte e vida, ruptura das fronteiras entre gêneros, papel dramatúrgico do performer, que se revelam juntos nos seus Stücke, parecem então verdadeiramente restituir um sentido turbado, atual e personalíssimo à idéia de Gesamtkunstwerk: um teatro total que renuncia a uma concepção apriorística harmonizadora a favor de uma contraposição heterogênea e polifônica de elementos "fora do lugar", que encontram de vez em quando a legitimidade das suas relações recíprocas somente no interior do processo criativo e dramatúrgico de cada obra.

É esta busca constante de sentido a partir do território por muito tempo culturalmente desvalorizado da dança, e por ela artisticamente e antropologicamente também reivindicado e revalorizado como um inalienável nível primário da criação teatral, que faz sim que Pina Bausch possa ser apontada, e por nós hoje honorificada, entre os maiores criadores/inovadores contemporâneos do teatro ocidental. 